\title{
Activists blame US policies for Uganda's condom shortage
}

Refuting allegations by activists, an official of Uganda's health ministry says the country is not in the throes of a condom shortage.

Health campaigners charge that condoms have been alarmingly scarce for more than ten months, a situation they say is undermining one of the most successful HIV-prevention programs in Africa. Under US pressure, they say, the Ugandan government is increasingly promoting abstinence and monogamy as anti-HIV tactics, rather than all three parts of its 'Abstinence, Being faithful and Condoms' (ABC) strategy.

Just days after the condom dispute erupted, the Global Fund to Fight AIDS, Tuberculosis and Malaria also announced the temporary suspension of \$201 million in committed grants to Uganda, on grounds of "serious mismanagement" by the health ministry.

Still, Elizabeth Madraa, who manages the Ugandan Ministry of Health's AIDS and STD program, says 20 million condoms have been distributed in the country since August. "Currently we are not having condom shortages," she says, adding that another 60 million condoms are in warehouses awaiting distribution or testing. The Global Fund is expected-despite its recent action-to ship in 55 million more by the end of September.

But the 20 million condoms now in distribution arrived as an emergency shipment from Europe in April and sat in storage for a full three months before reaching the public, notes Jodi Jacobson, executive director of the Center for Health and Gender Equity. What's more, she adds, only an additional 10 million condoms from the government and nonprofit groups are currently in circulation. And those supplies are nowhere near enough.

"Estimates are that at least 120 to 150 million condoms are needed in Uganda each year for HIV prevention alone," says Jacobson. "If this is not a crisis, I don't know what is."

Uganda has recently begun requiring that pretested international condoms go through another round of quality testing upon arriving in the country. Due to a new import fee, the price of condoms in shops has also spiked from $\$ 0.16$

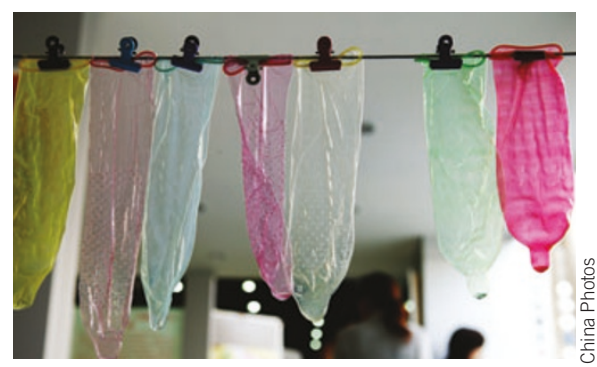

The US government's emphasis on abstinence may have precipitated Uganda's condom crisis. to $\$ 0.54$ for a package of three. District hospitals and government clinics, which previously dispensed condoms for free, are drained of supplies, says Beatrice Were of ActionAid in Uganda.

Uganda's First Lady Janet Museveni, a conservative evangelical Christian, is meanwhile vigorously promoting the abstinence message, prescribing 'virginity pledges' and reversing procondom billboard statements, Were adds.

Jacobson says about \$20 million under President Bush's emergency plan for AIDS relief has already gone this year to Ugandan HIV prevention efforts. Based on grant agreements and internal state documents, she says, at least $56 \%$ of that money has been targeted at abstinence-only initiatives.

Mark Dybul, the deputy US Global AIDS Coordinator, dismissed suggestions that the Ugandan condom shortage was motivated by either the Bush administration or the Ugandan government's stance on abstinence. Rather, he says, it arose due to a nationwide condom recall in October 2004 after overseas testing authorities found a faulty Ugandan batch. The recall "is the only way to rebuild confidence in the product, and it is exactly what any other government, including in Europe or North America, would do when faced with similar circumstances," Dybul says.

Paroma Basu, Madison

\section{Diabetes groups question whether 'metabolic syndrome' exists}

What's in a name? A great deal, according to some diabetes organizations.

The American Diabetes Association (ADA) and the European Association for the Study of Diabetes say the term 'metabolic syndrome' creates confusion. In a joint paper published in September, they question whether the term, which describes a cluster of certain risk factors for heart disease, counts as a syndrome at all (Diabetes Care 28, 2289-2304; 2005,

Diabetologia doi:10.1007/s00125-005-1876-2).

There is no evidence as yet to attribute the symptoms of metabolic syndrome to a common cause, says Richard Kahn, the ADA's chief scientific and medical officer. Diagnosing individuals with this term misleads them to believe they have a unique disease, he says.

Kahn's co-author on the paper, John Buse of the University of North Carolina in Chapel Hill, says the term distracts some people from the threat of individual risk factors. "Patients would come up to me and say 'Oh well, I have diabetes, but I don't have metabolic syndrome," he notes. Buse says treating risk factors-such as high blood pressure and obesity-separately is a better approach.

Definitions of metabolic syndrome vary widely. One group describes a person with the syndrome as having a large waist circumference combined with hypertension, low levels of 'good' cholesterol and high levels of glucose and triglycerides. Another common definition relies on the body mass index instead of waist size.

To resolve the differences, the International Diabetes Federation in April gathered a task force of 21 experts who arrived at a consensus. Their new description evaluates the waist size component of the equation according to ethnicity. For example, a man of European descent would have to have a waist circumference greater than 93 centimeters, whereas a Japanese male would meet the criterion with a waist circumference larger than 84 centimeters. This takes into account differences in body build among ethnic groups, says Sir George Alberti, past president of the organization and co-chair of the task force.

Using the term 'metabolic syndrome' can help gently remind overweight individuals of the importance of a healthier lifestyle, he says. "It is less confrontational than saying to a patient 'You are grossly overweight, and you have high blood pressure, and your blood lipids are too high."

But some researchers dismiss the skepticism about metabolic syndrome as the result of diabetes organizations wanting to protect their professional turf.

The debate over metabolic syndrome looks set to continue for some time. In response to the recent objections to the term, organizations such as the American Association of Clinical Endocrinologists have begun reassessing its use. "We have an obligation to clarify the confusion as to whether metabolic syndrome exists," says Jeffrey Mechanick, chairman of the association's nutrition committee.

Roxanne Khamsi, New York 